\title{
Magnesium upregulates insulin receptor and glucose transporter-4 in streptozotocin-nicotinamide-induced type-2 diabetic rats
}

\author{
Ayodele Olufemi Morakinyo ${ }^{1}$, Titilola Aderonke Samuel ${ }^{2}$, Daniel Abiodun Adekunbi ${ }^{3}$ \\ ${ }^{1}$ Department of Physiology, College of Medicine, University of Lagos, Lagos, Nigeria; ${ }^{2}$ Department of Biochemistry, \\ College of Medicine, University of Lagos, Nigeria; ${ }^{3}$ Department of Physiology, Benjamen S. Carson (Snr) \\ School of Medicine, Babcock University, Nigeria \\ E-mail:aomorakinyo@cmul.edu.ng
}

Objective. We investigated the effects of magnesium supplementation on glucose tolerance, insulin sensitivity, oxidative stress as well as the concentration of insulin receptor and glucose transporter-4 in streptozotocin-nicotinamide induced type-2 diabetic (T2D) rats.

Methods. Rats were divided into four groups designated as: 1) control (CTR); 2) diabetic untreated (DU);3) diabetic treated with $1 \mathrm{mg}$ of $\mathrm{Mg} / \mathrm{kg}$ diet (Mg1-D); and 4) diabetic treated with $2 \mathrm{mg}$ of $\mathrm{Mg} / \mathrm{kg}$ diet (Mg2-D). T2D was induced with a single intraperitoneal (i.p.) injection of freshly prepared streptozotocin $(55 \mathrm{mg} / \mathrm{kg})$ after an initial i.p. injection of nicotinamide $(120 \mathrm{mg} / \mathrm{kg})$. Glucose tolerance, insulin sensitivity, lipid profile, malondialdehyde (MAD) and glutathione content, insulin receptors (INSR) and glucose transporter-4 (GLUT4), fasting insulin and glucose levels were measured, and insulin resistance index was calculated using the homeostatic model assessment of insulin resistance (HOMA-IR).

Results. Magnesium supplementation improved glucose tolerance and lowered blood glucose levels almost to the normal range. We also recorded a noticeable increase in insulin sensitivity in Mg-D groups when compared with DU rats. Lipid perturbations associated T2D were significantly attenuated by magnesium supplementation. Fasting glucose level was comparable to control values in the Mg-D groups while the HOMA-IR index was significantly lower compared with the DU rats. Magnesium reduced MDA but increased glutathione concentrations compared with DU group. Moreover, INSR and GLUT4 levels were elevated following magnesium supplementation in $\mathrm{T} 2 \mathrm{D}$ rats.

Conclusion. These findings demonstrate that magnesium may mediate effective metabolic control by stimulating the antioxidant defense, and increased levels of INSR and GLUT4 in diabetic rats.

Key words: insulin receptor; glucose transporter-4; magnesium; insulin; glucose; type-2 diabetes mellitus; metabolism

Type 2 diabetes mellitus (T2DM) is a chronic metabolic disease characterized by hyperglycemia. The pathogenesis of T2DM involves progressive development of insulin resistance and a relative deficiency in insulin secretion, leading to overt hyperglycemia (Cohen 2006; Bergman 2013). Insulin resistance is often the consequence of reduced sensitivity of the insulin receptor (INSR) to insulin. Insulin controls glucose homeostasis by stimulating the clearance of glucose into skeletal muscle and, to a lesser degree, liver and adipose tissue. It has been reported that glucose uptake is mediated by a family of glucose transport proteins, which are known to be expressed in specific tissues. Among these proteins, glucose trans- 
porter-4 (GLUT4), is the major glucose transporter isoform in tissues that exhibit insulin-stimulated glucose uptake, such as adipose tissue and skeletal muscle. Insulin stimulates glucose transport in these two tissues by eliciting the translocation of GLUT4 from an intracellular pool to the plasma membrane (Charron et al. 1990). Furthermore, defects at the level of GLUT4 content have been observed in skeletal muscles and adipose tissue of insulin resistant and type 2 diabetic rodents (Zisman et al. 2000; Abel et al. 2001) and humans (Okuno et al. 1995; Yamada et al. 1999). Therefore, it appears that the concentration of GLUT4 in insulin target tissues influences the regulation of glucose uptake and metabolism as well as reflect the situation of whole-body insulin resistance, which is a major factor in the pathogenesis of T2DM.

As mentioned above, INSR plays a pivotal role in the metabolic actions of insulin. There is substantial evidence that the ability of INSR to auto-phosphorylate and phosphorylate intracellular substrates is essential for its mediation of the complex cellular responses to insulin (Chang et al. 2004). The key role of INSR in insulin action is demonstrated by the observation that targeted deletion of the INSR gene in neonatal life results in severe diabetic ketoacidosis (Accili et al. 1996; Joshi et al. 1996). In addition, alterations of INSR in specific tissues via genetic manipulation have been shown to produce varying degrees of insulin resistance and diabetes in mice (Bruning et al. 1998; Kulkarni et al. 1999; Mauvais-Jarvis et al. 2000; Kitamura et al. 2003).

Magnesium ( $\mathrm{Mg})$ is an essential mineral for human health, including energy homeostasis, protein synthesis, and DNA stability (de Baaij et al. 2015). As a cofactor of several enzymes, it modulates energy metabolism, carbohydrate oxidation, and glucose transport across the cell membrane (Garfinkel and Garfinkel 1988; Paolisso et al. 1990). Hypomagnesia has been suggested to impair insulin secretion and action and thereby worsening the control of diabetes (Rude 2012). Similarly, evidence from clinical studies have shown that hypomagnesia is associated with insulin resistance in both diabetic (Humphries et al. 1999; Lima et al. 2009) and non-diabetic healthy individuals (Nadler et al. 1993). Recent studies have suggested that increased $\mathrm{Mg}$ intake is associated with lower fasting glucose and insulin level (Hruby et al. 2013) as well as lower risk of T2D (Dong et al. 2011). Mg has also been reported to improve diabetes (Soltani et al. 2005a,b,c; 2007) and diabetic complications (Kisters et al. 2006; Li et al. 2013). In addition, there is abundant literature evidence indicating that $\mathrm{Mg}$ regulates insulin at levels such as secretion, receptor-binding, and activity (Barbagallo et al. 2003; Takaya et al. 2004; Barbagallo and Dominguez 2007). $\mathrm{Mg}$ is essential for autophosphorylation of INSR (Vicario and Bennun 1990; Vinals et al. 1997) leading to the translocation of GLUT4 to the plasma membrane thereby facilitating glucose transport and lowering blood glucose levels (Leto and Saltiel 2012).

Although a close association between hypomagnesia and T2D has been established; and the role of $\mathrm{Mg}$ supplementation in the management of glucose homeostasis has been reported severally; however, whether Mg modulates INSR and GLUT4 in a T2D model to control glucose homeostasis is not clearly defined. Thus, here we measured markers related to glucose metabolism such as glucose tolerance, insulin sensitivity, fasting insulin, homeostasis model of risk assessment-insulin resistance (HOMA-IR), lipid profile, malondialdehyde and glutathione. Additionally, we measured the level of INSR and GLUT4 in insulinresponsive skeletal muscle.

\section{Materials and Methods}

Animals and Diet. Thirty-two male Sprague-Dawley rats aged 10 weeks (weight $150 \pm 20$ g) were selected and maintained under a controlled environment with 12-hour light/dark cycles and a temperature of $24 \pm 2{ }^{\circ} \mathrm{C}$. Animals were divided into four groups $(n=8)$ : control (CTR); diabetic untreated (DU); diabetic treated with $1 \mathrm{mg}$ of $\mathrm{Mg} / \mathrm{kg}$ diet (Mg1-D); and diabetic treated with $2 \mathrm{mg}$ of $\mathrm{Mg} / \mathrm{kg}$ diet (Mg2-D). The 3 experimental diets were from the same preparation of ingredient mixing using AIN-93G formulation (Table 1) to ensure identical concentrations of all nutrients except for $\mathrm{Mg}$; the AIN-93G basal diet was supplemented with 0,1 or $2 \mathrm{mg} \mathrm{MgSO}_{4}$ per $\mathrm{kg}$. CTR and DU rats were given basal diet that serves as vehicle throughout the 4 -week period of dietary intervention. Food intake was measured daily and body weight twice weekly in all groups. All animal experiments were conducted according to institutional guidelines congruent with the NIH Guide for the Care and Use of Laboratory Animals (NRC 2011).

Induction of diabetes. T2D was induced as described by Masiello et al. (1998) with amendment. Briefly, overnight-fasted rats received a single intraperitoneal (i.p.) injection of freshly prepared nicotinamide (120 mg/kg b.w.). Five minutes before, $55 \mathrm{mg} / \mathrm{kg}$ b.w. of freshly prepared streptozotocin (STZ) dissolved in $0.1 \mathrm{M}$ citric buffer ( $\mathrm{pH} 4.5)$ was administered via an i.p. injection. Control rats were injected with vehicle alone. On the $5^{\text {th }}$ day, blood glucose levels were determined with a glucometer 
(Accu-Chek, Roche Diagnostics, Germany) using blood drops obtained from an incision made in each tail vein and animals with blood glucose level above $200 \mathrm{mg} / \mathrm{dL}$ were considered to be diabetic.

Glucose tolerance test (GTT). At the end of the feeding protocol, rats were kept starved overnight $(12 \mathrm{~h})$ and an oral GTT was performed. Normal water was supplied during the food deprivation period. Basal blood glucose concentrations were measured in blood taken from the tail vein using glucometer (Roche Diagnostics, Germany). The rats were administered $2 \mathrm{~g} / \mathrm{kg}$ body weight of glucose as a $40 \%$ aqueous solution via oral gavage. Tail vein blood samples were taken at 30,60, 90, 120 and 180 min following glucose administration.

Insulin tolerance test. For the insulin tolerance test (ITT), rats that had been fasted for $4 \mathrm{~h}$ were injected i.p. with regular human insulin (Humulin, $0.75 \mathrm{U} / \mathrm{kg}$ body weight). The blood glucose concentrations were monitored from the blood sample obtained from the tail vein before ( $0 \mathrm{~min}$ ) and $15,30,60$, 90, 120 and $180 \mathrm{~min}$ after insulin injection.

Biochemical analysis and insulin resistance (IR) index. Fasting plasma glucose was determined with the Accu Chek glucometer and insulin was assayed using the ELISA Kits (Elabscience, Wuhan, China)

Table 1

Composition of basal diet ( $\mathrm{g} / \mathrm{kg}$ diet)

\begin{tabular}{lc}
\hline Component & Content \\
\hline Corn starch & 530 \\
Sucrose & 100 \\
Soya bean & 70 \\
Casein & 200 \\
L-Cystine & 3 \\
Mineral mix & 35 \\
Vitamin mix & 10 \\
Choline bitartrate & 2.5 \\
TBHQ & 0.014 \\
Fibre & 50 \\
Fat (\% kcal) & 17.3 \\
Carbohydrate (\% kcal) & 63.9 \\
Protein (\% kcal) & 18.8 \\
Energy (kcal) & 3840 \\
\hline
\end{tabular}

${ }^{*} \mathrm{Mg}$ concentration $=507 \mathrm{mg} / \mathrm{kg}$ diet per the manufacturer's instruction. All the reagents and samples were brought to room temperature before conducting the experiment. Homeostatic model assessment of insulin resistance (HOMA-IR) expressed as an index of insulin resistance was calculated using the homeostasis model assessment: HOMA-IR = fasting glucose $(\mathrm{mg} / \mathrm{dL}) \times$ fasting insulin $(\mathrm{mU} / \mathrm{L}) / 405$ (Matthews et al. 1988). Retroorbital blood samples were taken under light ether anesthesia following over-night (12-h) fasting, blood was collected in an Eppendorf tube, allowed to clot at room temperature, and centrifuged at $5000 \mathrm{rpm}$ for $5 \mathrm{~min}$. Serum was thereafter removed and used for biochemical measurements. Serum concentrations of triglyceride (TRIG), cholesterol (CHOL), low-density lipoprotein (LDL) and high-density lipoprotein (HDL) were determined with an automatic blood chemical analyzer (BT 2000 Plus, Germany).

Quantification of malondialdehyde level and glutathione activity. To determine the effects of $\mathrm{Mg}$ supplementation on lipid peroxidation and antioxidant enzyme activity, plasma samples were prepared by centrifugation of the whole blood (sodium EDTA as anticoagulant) from the retroorbital bleeding. As a marker of lipid peroxidation, the level of malondialdehyde (MDA) was measured by the method of Uchiyama and Mihara (1978) as thiobarbituric acid reactive substances (TBARS). The development of a pink complex with absorption maximum at $535 \mathrm{~nm}$ was taken as an index of lipid peroxidation. Reduced glutathione (GSH) was determined using the method described by van Dooran et al. (1978). The GSH determination method is based on the reaction of Ellman's reagent 5, 5' dithiobis (2-nitrobenzoic acid) DNTB) with the thiol group of GSH at $\mathrm{pH} 8.0$ to produce 5-thiol-2-nitrobenzoate which is yellow at $412 \mathrm{~nm}$.

Level of INSR and GLUT4. The skeletal tissue homogenate was used for the determination of INSR and GLUT4 concentrations. The gastrocnemius muscle was homogenized in 9-volumes of ice-cold $0.1 \mathrm{mM}$ phosphate buffer saline ( $\mathrm{pH}$ 7.4) to prepare $10 \%$ homogenate. The homogenate was then centrifuged for $5 \mathrm{~min}$ at $5000 \times \mathrm{g}$ to get the supernatant used for the measurement. These parameters were determined using enzyme immunoassay (EIA) kit (Elabscience Biotechnology Co., China). The procedure specified in the manufacturer's manual for the kits were followed. A 96-well microtiter plate was used to conduct the analysis.

Statistical analysis. Data are expressed as mean \pm standard error of mean (SEM) and analyzed using the ANOVA followed by SNK post-hoc test. A p-value below 0.05 was considered to be statistically significant. 
All the analyses were carried out using the GraphPad Instat Version 3.05 for Window Vista, GraphPad Software, San Diego California, USA.

\section{Results}

Food and water intake. With or without $\mathrm{Mg}$ intake, diabetic rats exhibited increased food intake compared with control. The DU and both Mg-treated groups significantly consumed $(\mathrm{p}<0.05)$ more feed by comparison with the control (CTR) group. However, the difference between the Mg-treated diabetic groups and CTR were found not to be statistically significant $(\mathrm{p}>0.05)$ (Table 2).

As for water intake, there was a significant increase in $\mathrm{Mg} 2-\mathrm{D}$ rats when compared with CTR and DU rats. Even though the water intake of CTR was lower than that of the DU rats, it progressively reached level of statistical significance only at week 3 and 4 of study (Table 2).

Body weight and weight gain. There was no significant difference in the body weight of among groups before treatment. At the end of 4-week experimental period, a significant increase $(\mathrm{p}<0.05)$ in body weight of control group was $28.5 \mathrm{~g}$ (15.36\% increase). However, there was a notable weight loss of $24.0 \mathrm{~g}(14.12 \%$ decrease), $10.7 \mathrm{~g}$ (5.85\% decrease) and $25.4 \mathrm{~g}$ (14.53\% decrease) in the DU, Mg1-D and Mg2-D groups respectively (Table 3 ).

Glucose tolerance. Before glucose loading, all groups except the DU rats showed similar blood glu- cose concentration after overnight fasting $(0 \mathrm{~min})$. The DU rats exhibited a significantly higher blood glucose level at all time-points compared with other groups (CTR, Mg1-D and Mg2-D) and also failed to return to their time-zero value within 180 -min post glucose loading. Although, glucose challenge dramatically raised the blood glucose level of Mg1-D and $\mathrm{Mg} 2-\mathrm{D}$ rats compared with control rats at 30 and $60 \mathrm{~min}$; however, these groups showed noticeable improvement in oral glucose tolerance as the blood glucose levels were remarkably lower than DU rats at all time-points (Figure 1).

Insulin tolerance. In response to insulin challenge, the blood glucose levels of all groups decreased

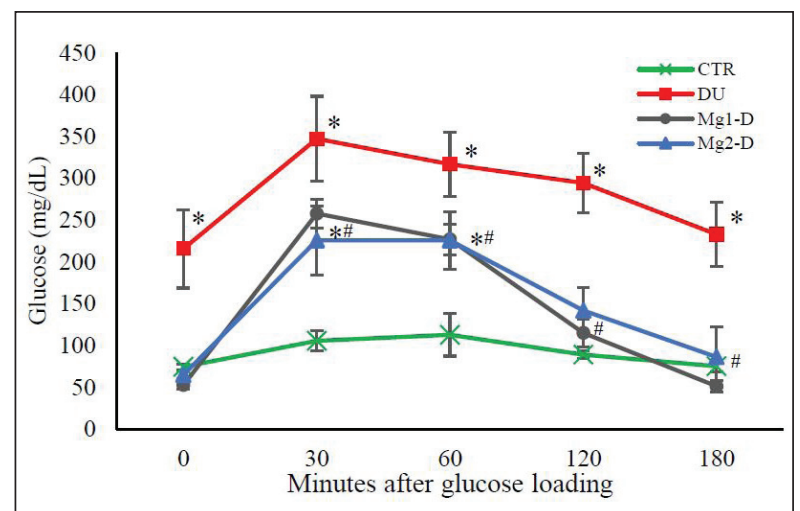

Figure 1. Effect of magnesium supplementation on glucose during glucose tolerance test in diabetic rats. Data expressed as mean \pm SEM, ${ }^{*} \mathrm{p}<0.05$ vs. CTR; ${ }^{*} \mathrm{p}<0.05$ vs. DU.

Table 2

Effect of magnesium supplementation on food and water intake

\begin{tabular}{|c|c|c|c|c|}
\hline \multirow[b]{2}{*}{ Groups } & \multicolumn{4}{|c|}{ Food Intake (g) } \\
\hline & Week 1 & Week 2 & Week 3 & Week 4 \\
\hline CTR & $23.04 \pm 1.86$ & $26.33 \pm 0.69$ & $30.04 \pm 0.90$ & $30.09 \pm 1.05$ \\
\hline DU & $32.37 \pm 1.51^{*}$ & $37.34 \pm 3.96^{*}$ & $42.43 \pm 3.27^{\star}$ & $41.09 \pm 1.97^{*}$ \\
\hline Mg1-D & $29.87 \pm 2.09^{*}$ & $36.59 \pm 2.17^{*}$ & $42.29 \pm 3.78^{*}$ & $46.68 \pm 1.17^{*}$ \\
\hline \multirow[t]{2}{*}{ Mg2-D } & $34.81 \pm 1.58^{*}$ & $39.97 \pm 1.13^{*}$ & $44.86 \pm 0.80^{*}$ & $47.08 \pm 0.98^{* \#}$ \\
\hline & \multicolumn{4}{|c|}{ Water Intake (ml) } \\
\hline Groups & Week 1 & Week 2 & Week 3 & Week 4 \\
\hline Control & $37.62 \pm 1.57$ & $46.42 \pm 1.59$ & $46.08 \pm 1.90$ & $54.88 \pm 2.06$ \\
\hline DU & $39.05 \pm 2.08$ & $48.52 \pm 2.40$ & $62.72 \pm 1.07^{*}$ & $64.73 \pm 3.78^{*}$ \\
\hline Mg1-D & $38.10 \pm 2.20$ & $52.58 \pm 2.31$ & $53.99 \pm 4.03$ & $66.79 \pm 2.83^{\star \#}$ \\
\hline Mg2-D & $51.47 \pm 4.12^{* \# a}$ & $59.28 \pm 3.44^{\star * a}$ & $87.67 \pm 2.31^{\star \# a}$ & $97.98 \pm 1.31^{\star * a}$ \\
\hline
\end{tabular}

Abbreviations: DU - diabetic untreated rats; Mg1-D - diabetic rats treated with 1mg of mg/kg diet; Mg2-D - diabetic rats treated with $2 \mathrm{mg}$ of $\mathrm{mg} / \mathrm{kg}$ diet. ${ }^{*} \mathrm{p}<0.05$ vs. Control, ${ }^{*} \mathrm{p}<0.05$ vs. $\mathrm{DU},{ }^{a} \mathrm{p}<0.05$ vs. Mg1-D. 
rapidly (Figure 2). The blood glucose level of DU rats was significantly $(\mathrm{p}<0.05)$ higher than that of control at all time-points. Compared with DU rats, no sig-

Table 3

Effect of magnesium supplementation on body weight and weight gain

\begin{tabular}{lcccc}
\hline Groups & IBW $(\mathrm{g})$ & FBW $(\mathrm{g})$ & WG $(\mathrm{g})$ & \% WG \\
\hline Control & $185.5 \pm 7.29$ & $214.0 \pm 2.11$ & +28.5 & +15.36 \\
DU & $170.0 \pm 2.58$ & $146.2 \pm 6.66^{*}$ & -24.0 & -14.12 \\
Mg1-D & $182.3 \pm 3.93$ & $171.7 \pm 11.92^{\star *}$ & -10.7 & -5.85 \\
Mg2-D & $174.8 \pm 9.05$ & $149.4 \pm 11.18^{\star a}$ & -25.4 & -14.53 \\
\hline
\end{tabular}

Abbreviations: IBW - initial body weight; FBW - final body weight; WG - weight gain; DU - diabetic untreated rats;

Mg1-D - diabetic rats treated with $1 \mathrm{mg}$ of $\mathrm{mg} / \mathrm{kg}$ diet; $\mathrm{Mg} 2-\mathrm{D}$ - diabetic rats treated with $2 \mathrm{mg}$ of $\mathrm{mg} / \mathrm{kg}$ diet.

${ }^{*} \mathrm{p}<0.05$ vs. Control; ${ }^{*} \mathrm{p}<0.05$ vs. DU; ${ }^{a} \mathrm{p}<0.05$ vs. Mg1-D.

Table 4

Effect of magnesium supplementation on blood glucose, insulin levels and HOMA-IR

\begin{tabular}{lccc}
\hline Groups & $\begin{array}{c}\text { Glucose } \\
(\mathrm{mg} / \mathrm{dL})\end{array}$ & $\begin{array}{c}\text { Insulin } \\
(\mathrm{mU} / \mathrm{L})\end{array}$ & HOMA-IR \\
\hline CTR & $74.4 \pm 3.32$ & $6.23 \pm 0.49$ & $1.14 \pm 0.09$ \\
DU & $215.5 \pm 46.9^{*}$ & $9.35 \pm 0.18^{*}$ & $4.97 \pm 0.25^{*}$ \\
Mg1-D & $52.4 \pm 4.30^{* *}$ & $8.91 \pm 0.21^{*}$ & $1.28 \pm 0.18^{* *}$ \\
Mg2-D & $64.8 \pm 5.04^{*}$ & $8.26 \pm 0.22^{*}$ & $1.31 \pm 0.13^{* *}$ \\
\hline
\end{tabular}

Abbreviations: DU - diabetic untreated rats; Mg1-D - diabetic rats treated with $1 \mathrm{mg}$ of $\mathrm{mg} / \mathrm{kg}$ diet; $\mathrm{Mg} 2-\mathrm{D}$ - diabetic rats treated with $2 \mathrm{mg}$ of $\mathrm{mg} / \mathrm{kg}$ diet.

${ }^{*} \mathrm{p}<0.05$ vs. Control, ${ }^{*} \mathrm{p}<0.05$ vs. DU.

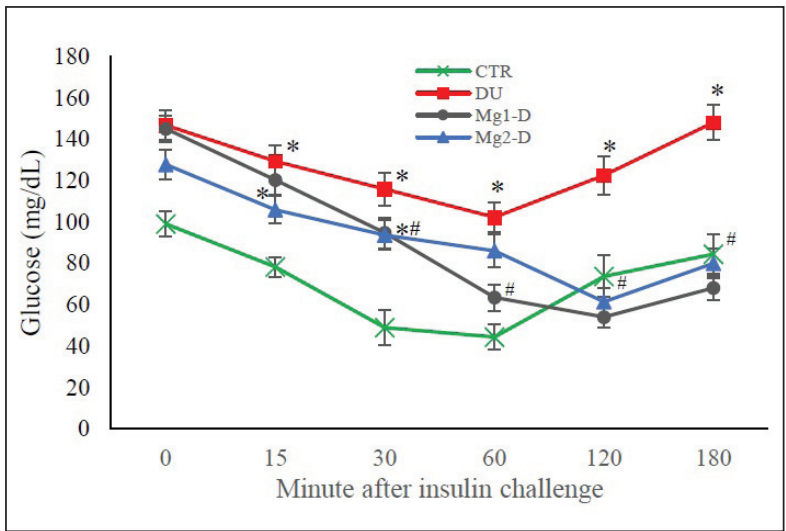

Figure 2. Effect of magnesium supplementation on glucose during insulin tolerance test in diabetic rats. Data expressed as mean \pm SEM, ${ }^{*} \mathrm{p}<0.05$ vs. CTR; ${ }^{*} \mathrm{p}<0.05$ vs. DU. nificant difference in glucose level was found at 15 , 30 and 60 min interval in the Mg1-D and Mg2-D rats. However, the blood glucose level of both Mg-D groups at 120 and $180 \mathrm{~min}$ were significantly lower $(\mathrm{p}<0.05)$ than that of DU.

Glucose, insulin, and IR index. Fasting glucose and insulin levels were 290\% and 150\% higher in DU rats than in control rats, respectively. Supplementation with $\mathrm{Mg}$ significantly $(\mathrm{p}<0.05)$ reduced plasma glucose levels when compared with DU rats. The insulin level was however significantly higher $(\mathrm{p}<0.05)$ in the all groups when compared with the control group. As shown in Table 4, IR indices calculated by homeostasis model assessment in DU group were significantly higher $(\mathrm{p}<0.05)$ compared with control group ( $430 \%$ increase). However, HOMA-IR was significantly reduced $(\mathrm{p}<0.05)$ in $\mathrm{Mg} 1-\mathrm{D}$ and $\mathrm{Mg} 2-\mathrm{D}$ rats (1.28 \pm 0.18 and $1.31 \pm 0.13$, respectively) compared with control rats $(4.97 \pm 0.25)$.

Lipid profile. CHOL, TRIG and HDL levels in DU rats were significantly higher $(\mathrm{p}<0.05)$ than those in the control rats. Mg supplementation markedly reduced $(p<0.05)$ the increase in serum levels of these lipids induced by diabetes, indicating that $\mathrm{Mg}$ intake protected against diabetes-induced lipid disorder (Figure 3).

MDA and GSH level. Diabetic rats had a significantly increased $(\mathrm{p}<0.05)$ plasma MDA levels when compared with control rats (Figure 4). This effect was attenuated by $\mathrm{Mg}$ supplementation in diabetic rats. In addition, there was a significantly decrease $(\mathrm{p}<0.05)$ in the plasma GSH but Mg administration abated the depletion and was accompanied by a recovery of the antioxidant enzyme level (Figure 4).

INSR and GLUT4 content. The level of INSR and GLUT4 concentration in the skeletal muscle samples was quantified using ELISA techniques. In gastrocnemius muscle, INSR and GLUT4 was significantly decreased $(p<0.05)$ by diabetes, whereas Mg treatment clearly attenuated the diabetes-induced decrease in the concentration of both proteins (Figure 5).

\section{Discussion}

The present study showed deranged glucose metabolism, altered lipid profile, oxidative stress and insulin resistance following streptozotocin-nicotinamide-induced diabetes in rats, a finding that is consistent with the literature and support the use of streptozotocin-nicotinamide model as a cost-effective prototype of type 2 diabetes mellitus (Masiello et al. 1998; Masiello 2006; Tangvarasittichai 2015). Dietary magnesium supplementation in a phase of 


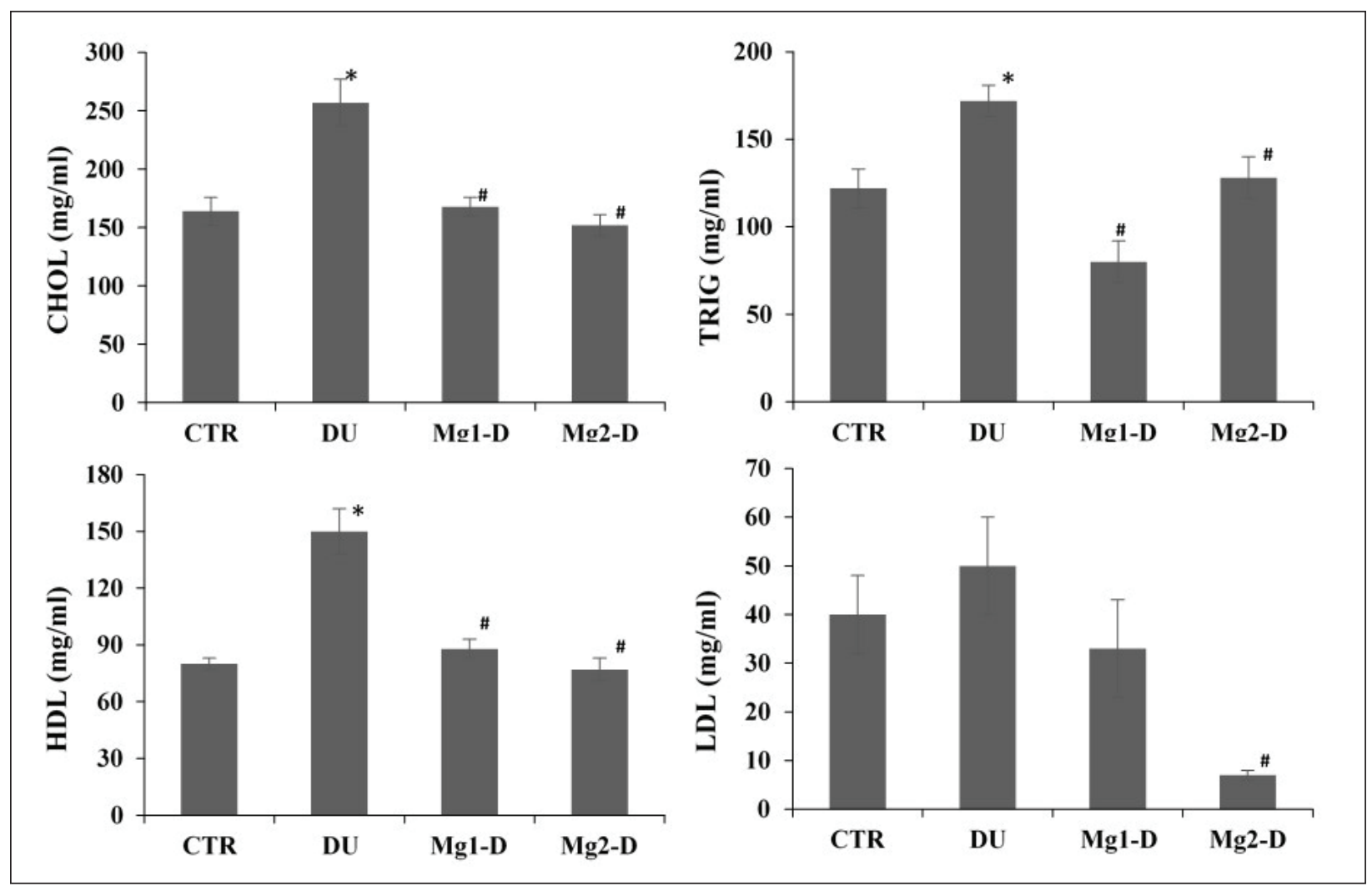

Figure 3. Effect of magnesium supplementation on cholesterol (CHOL), triglyceride (TRIG), high-density lipoprotein (HDL) and low-density lipoprotein (LDL) levels in diabetic rats. Data expressed as mean $\pm \mathrm{SEM},{ }^{*} \mathrm{p}<0.05 \mathrm{vs}$. CTR; ${ }^{*} \mathrm{p}<0.05$ vs. DU.

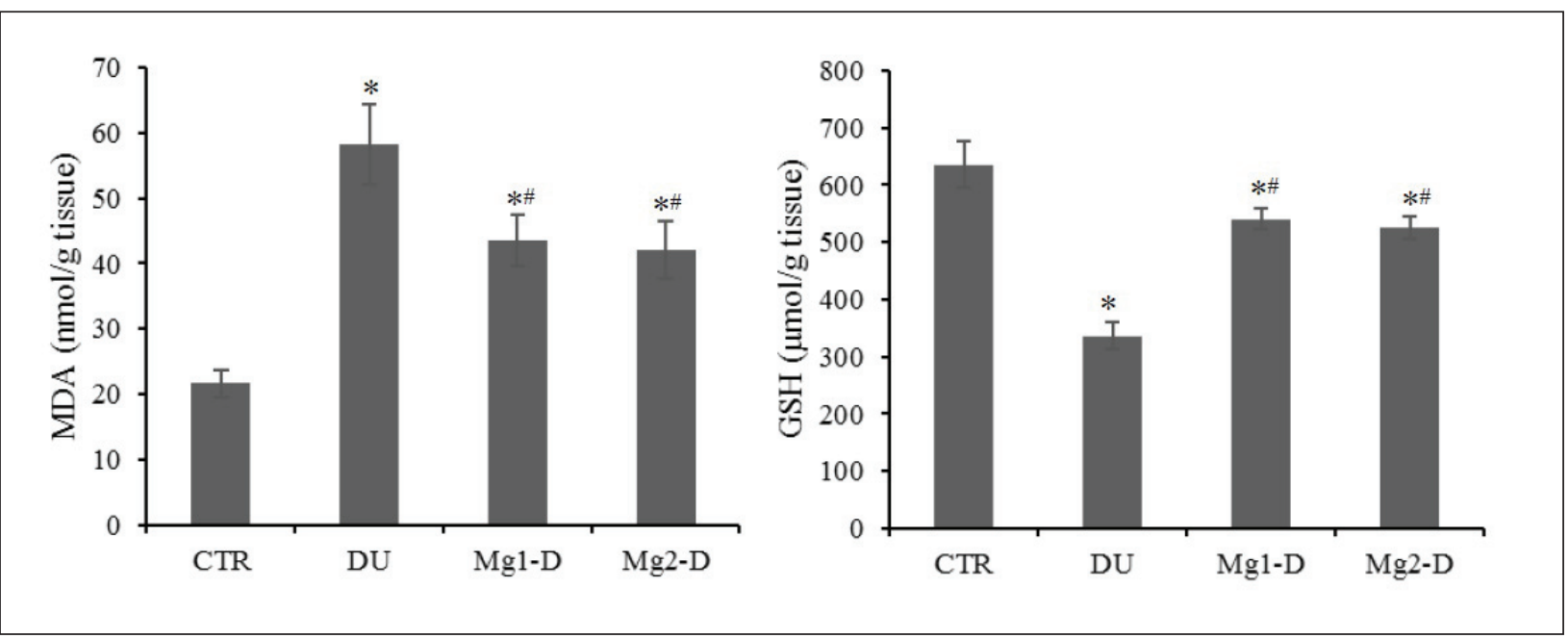

Figure 4. Effect of magnesium supplementation on malondialdehyde (MDA) and glutathione (GSH) levels in diabetic rats. Data expressed as mean $\pm \mathrm{SEM},{ }^{*} \mathrm{p}<0.05$ vs. CTR; ${ }^{*} \mathrm{p}<0.05$ vs. DU.

established diabetes mellitus ameliorated the above metabolic disorders and attenuated diabetes-induced decrease in INSR and GLUT4 content in the gastrocnemius muscles of diabetic rats. These find- ings demonstrate that magnesium may mediate effective metabolic control by modulating the quantity of INSR and GLUT4 in diabetic rats. The higher dose of $\mathrm{Mg}$ exerted more pronounced side effects mani- 


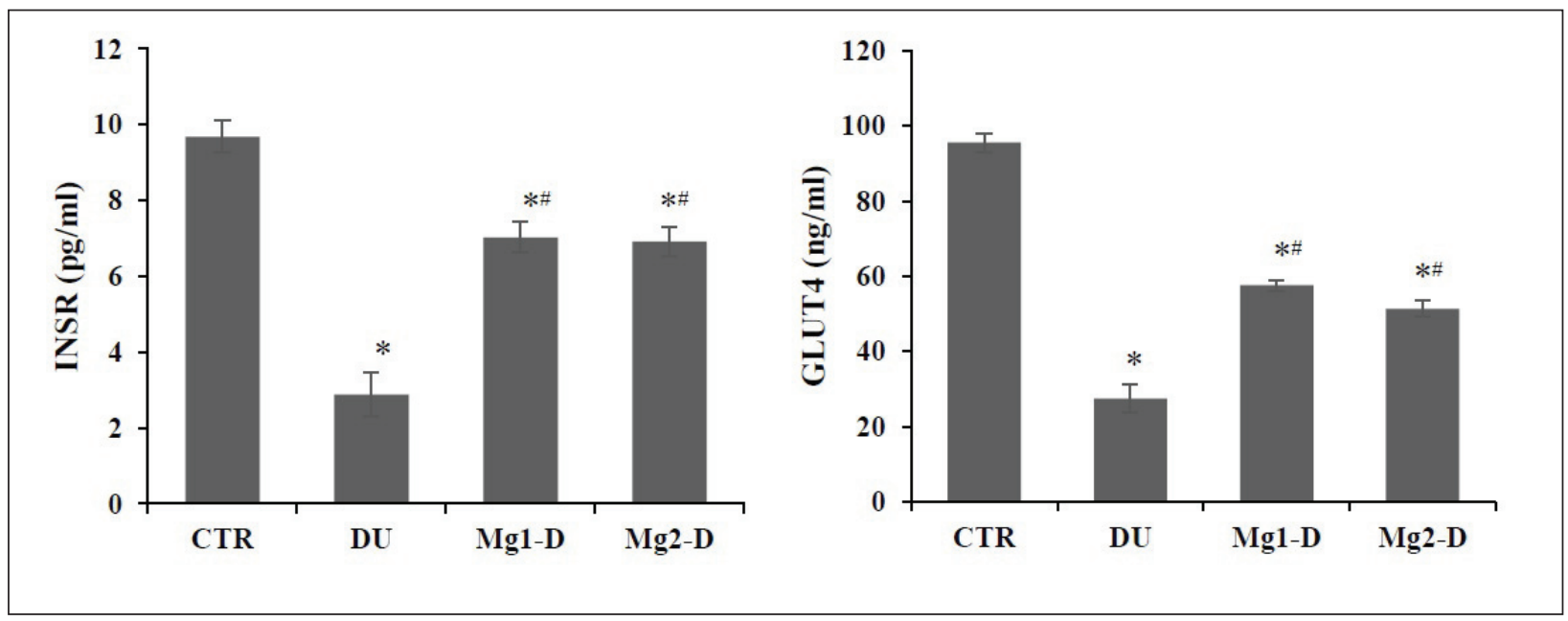

Figure 5. Effect of magnesium supplementation on insulin receptors (INSR) and glucose-transporter 4 (GLUT4) in diabetic rats. Data expressed as mean $\pm \mathrm{SEM},{ }^{\star} \mathrm{p}<0.05$ vs. CTR; ${ }^{*} \mathrm{p}<0.05$ vs. DU.

fested by enhanced water intake and lowered weight gain, while the beneficial effects of both doses of $\mathrm{Mg}$ were equal.

The characteristic symptoms of diabetes mellitus include polydipsia and weight loss that is accompanied by a polyphagia. In the present study, the significant reduction in body weight in diabetic compared with control rats despite increased food consumption is in accordance with previous reports (Irondi et al. 2016). The inverse relationship between body weight and food intake in the diabetic rats may be related to increased muscle wasting associated with diabetes mellitus (Ene et al. 2007) and this may also account for the variance between changes in body weight and food consumption. There may be a limited role for magnesium in body weight management under diabetic conditions, since magnesium supplementation showed no apparent effect on diabetes-induced weight loss in the current study. Additionally, polydipsia elicited by diabetes mellitus may have necessitated the observed increase in fluid intake in the diabetic animals, which was further aggravated by magnesium supplementation particularly at a higher dose. We observed watery faecal matter in the magnesium treated rats occurring concurrently with diabetes-induced polyuria (data not shown). This phenomenon may have triggered a compensatory increase in water intake as observed in this study.

Normal glucose tolerance is achieved by enhanced insulin secretion and sensitivity in the presence of a glucose challenge. Hence, decreased insulin secretion and/or loss of insulin sensitivity may result in impaired glucose tolerance (Festa et al. 2006). As expected, the diabetic untreated rats exhibited increased fasting blood glucose, impaired glucose tolerance and defective insulin sensitivity in a fashion consistent with earlier reports (Tahara et al. 2008; Mahmoud et al. 2012). Insulin resistant state as determined by HOMA-IR corroborates reduced sensitivity to insulin during the insulin tolerance test, and the induction of insulin resistance may possibly mediate the perturbation in glucose handling in the diabetic rats. Similarly, the diabetic untreated rats presented with dyslipidemia evident by high cholesterol and triglyceride levels. This result is similar to the report of Taheri Rouhi et al. (2017) where significant elevation of cholesterol and triglyceride levels were observed in streptozotocin-nicotinamide model of diabetes. Dietary magnesium supplementation for 4 weeks reversed insulin resistance, improved insulin sensitivity, enhanced glucose metabolism and prevented diabetes-induced lipid disorder. A beneficial effect of magnesium on glucose homeostasis and insulin sensitivity has been shown in non-diabetic hypomagnesaemia subjects leading to the suggestion that magnesium may be a natural insulin sensitizer (Mooren et al. 2011). The findings of this study are consistent with previous reports on magnesium intervention in human subject with T2D (Song et al. 2006) and validates the recent association between increased magnesium intake and lower risk of T2D (Hruby et al. 2013).

Persistent hyperglycemia and hyperlipidemia promotes increased production of reactive oxygen species in diabetes (Kumar et al. 2008; Vasconcelos et al. 2009). Free radical accumulation results in lipid 
peroxidation and depletion of antioxidant enzymes (Maritim et al. 2003). MDA reflects the level of lipid peroxidation in the body. In the current study, there was a drastic reduction in MDA level following dietary magnesium supplementation to diabetic rats and this datum indicates that magnesium inactivates lipid peroxidation and decreased free radical generation in line with the protective effect of magnesium against oxidative damage (Yavuz et al. 2013). In parallel to the development of oxidative stress in T2D is the impairment of the antioxidant defense system (Hasanain and Mooradian 2002; Zhang et al. 2010), however dietary magnesium treatment improved the oxidative status of these animals by reversing the depletion of plasma GSH content induced by T2D. The antioxidant property of magnesium may be related to its role as a co-factor in glutathione synthesis (Mills et al. 1986). Yavuz et al. (2013) have also shown that magnesium increases activities of antioxidant enzymes such as glutathione peroxidase, superoxide dismutase and catalase.

Eighty percent $(80 \%)$ of ingested glucose is consumed by the skeletal muscle cells and have the highest level of insulin stimulated glucose uptake. Consequently, skeletal muscles have become the main site of insulin resistance (Wu et al. 2016). When insulin binds to its receptor in the skeletal muscle, the activated downstream signaling pathways including phosphatidylinositol 3-kinase (PI 3-kinase) promote the transmembrane activity of GLUT4 which facilitates glucose uptake (Moraes-Vieira et al. 2016). Pharmacologic inhibition of PI 3-kinase activity by wortmannin completely blocks insulin-mediated glucose uptake in rats (Okada et al. 1994). Hence, the translocation of GLUT4 to the sarcolemma and the eventual concentration of GLUT4 governs the rate of glucose transport into fat and muscle cells
(Furtado et al. 2002; Watson et al. 2004). With the foregoing, defective insulin - insulin receptor activity and decreased GLUT4 arising from impaired cell membrane translocation of GLUT4 may play a significant role in the pathogenesis of type 2 diabetes (Yan et al. 2014). Magnesium is a co-factor that plays a key role in phosphorylation of insulin receptor as well as translocation of GLUT4 from the intracellular pool to the plasma membrane (Volpe 2013). The underlying mechanism by which magnesium exert glucose control may therefore involve a direct effect on insulin receptor as well as its downstream signaling processes. The present study showed that magnesium supplementation significantly increased INSR and GLUT4 level which were downregulated in an uncontrolled diabetic state. Since the intracellular level of magnesium correlates inversely with blood glucose level (Barbagallo et al. 2000), it therefore appears that the magnesium-induced upregulation of INSR and GLUT4 may be a potential mechanism by which magnesium maintains glucose homeostasis in T2D.

In conclusion, these data support a role for magnesium in glucose and lipid metabolism as well as insulin resistance in rat model of type 2 diabetes, which may be associated with the beneficial effect of magnesium in antioxidant defense as well as induction of increased INSR and GLUT4 proteins in the skeletal muscle. These findings provide a mechanistic basis for the use of magnesium supplements in the maintenance of glucose homeostasis in type 2 diabetes condition.

\section{Acknowledgement}

This research work was funded by the University of Lagos TETFUND Research Grant (CRC/TETFUND/ No. 2014/03).

\section{References}

Abel ED, Peroni O, Kim JK, Kim YB, Boss O, Hadro E, Minnemann T, Shulman GI, Kahn BB. Adipose selective targeting of the GLUT4 gene impairs insulin action in muscle and liver. Nature 409, 729-733, 2001.

Accili D, Drago J, Lee EJ, Johnson MD, Cool MH, Salvatore P, Asico LD, Jose PA, Taylor SI, Westphal H. Early neonatal death in mice homozygous for a null allele of the insulin receptor gene. Nat Genet 12, 106-109, 1996.

Barbagallo M, Gupta R, Dominguez LJ, Resnick LM. Cellular ionic alterations with aging: relation to hypertension and diabetes. J Am Soc Geriatrics 48, 1111-1116, 2000.

Barbagallo M, Dominguez LJ, Galioto A, Ferlisi A, Cani C, Malfa L, Pineo A, Busardo A, Paolisso G. Role of magnesium in insulin action, diabetes and cardio-metabolic syndrome X. Mol Aspects Med 24, 39-52, 2003.

Barbagallo M, Dominguez JL. Magnesium metabolism in type 2 diabetes, metabolic syndrome and insulin resistance. Arch Biochem Biophys 458, 40-47, 2007.

Bergman M. Pathophysiology of prediabetes and treatment implications for the prevention of type 2 diabetes mellitus. Endocrine 43,504-513, 2013. 
Bruning JC, Michael MD, Winnay JN, Hayashi T, Horsch D, Accili D, Goodyear LJ, Kahn CR. A muscle-specific insulin receptor knockout exhibits features of the metabolic syndrome of NIDDM without altering glucose tolerance. Mol Cell 2, 559-569, 1998.

Chang L, Chiang SH, Saltiel AR. Insulin signaling and the regulation of glucose transport. Mol Med 10, 65-71, 2004. Charron MJ, Katz EB, Olson AL. GLUT4 gene regulation and manipulation. J Bio Chem 274, 3253-3256, 1999.

Cohen P. The twentieth century struggle to decipher insulin signalling. Nat Rev Mol Cell Biol 7, 867-873, 2006.

de Baaij JHF, Hoenderop JGJ, Bindels RJM. Magnesium in man: implications for health and disease. Physiol Rev 95, $1-46,2015$.

Dong JY, Xun P, He K, Qin LQ. Magnesium intake and risk of type 2 diabetes: meta-analysis of prospective cohort studies. Diabetes Care 34, 2116-2122, 2011.

Ene AC, Nwankwo EA, Sambi LM. Alloxan-induced diabetes in arts and the effects of black caraway (Caramcarvi L.) oil on their body weight. J Phamacol Toxicol 3, 141-146, 2007.

Festa A, Williams K, D’Agostino R Jr, Wagenknecht LE, Haffner SM. The natural course of beta-cell function in nondiabetic and diabetic individuals: The insulin resistance atherosclerosis study. Diabetes 55, 1114-1120, 2006.

Furtado LM, Somwar R, Sweeney G, Niu W, Klip A. Activation of the glucose transporter GLUT4 by insulin. Biochem. Cell Biol 80, 569-578, 2002.

Garfinkel D, Garfinkel L. Magnesium and regulation of carbohydrate metabolism at the molecular level. Magnesium 7, 249-261, 1988.

Hasanain B, Mooradian AD. Antioxidant vitamins and their influence in diabetes mellitus. Curr Diab Rep 2, 448456, 2002.

Hruby A, Ngwa JS, Renstrom F, Wojczynski MK, Ganna A, Hallmans G. Higher magnesium intake is associated with lower fasting glucose and insulin, with no evidence of interaction with select genetic loci, in a meta-analysis of 15 CHARGE Consortium Studies. J Nutr 143, 345-353, 2013.

Humphries S, Kushner H, Falkner B. Low dietary magnesium is associated with insulin resistance in a sample of young, nondiabetic Black Americans. Am J Hypertens 12, 747-756, 1999.

Irondi EA, Oboh G, Akindahunsi AA. Antidiabetic effects of Mangifera indica Kernel Flour-supplemented diet in streptozotocin-induced type 2 diabetic in rats. Food Sci Nutr 4, 828-839, 2016.

Joshi RL, Lamothe B, Cordonnier N, Mesbah K, Monthioux E, Jami J, Bucchini D. Targeted disruption of the insulin receptor gene in the mouse results in neonatal lethality. Embo J 15, 1542-1547, 1996.

Kisters K, Gremmler B, Kozianka J, Hausberg M. Magnesium deficiency and diabetes mellitus. Clin Nephrol 65, 77-78, 2006.

Kitamura T, Kahn CR, Accili D. Insulin receptor knockout mice. Annu Rev Physiol 65, 313-332, 2003.

Kulkarni RN, Winnay JN, Daniels M, Bruning JC, Flier SN, Hanahan D, Kahn CR. Altered function of insulin receptor substrate-1-deficient mouse islets and cultured beta-cell lines. J Clin Invest 104, R69-R75, 1999.

Kumar G, Banu GS, Murugesan AG. Effect of Helicteres isora bark extracts on heart antioxidant status and lipid peroxidation in streptozotocin diabetic rats. J Appl Biomed 6, 89-95, 2008.

Leto D, Saltiel AR. Regulation of glucose transport by insulin: traffic control of GLUT4. Nat Rev Mol Cell Biol 13, 383-396, 2012.

Li B, Tan Y, Sun W, Fu Y, Miao L, Cai L. The role of zinc in the prevention of diabetic cardiomyopathy and nephropathy. Toxicol Mech Methods 23, 27-33, 2013.

Lima ML, Cruz T, Rodrigues LE. Serum and intracellular magnesium deficiency in patients with metabolic syndrome-evidences for its relation to insulin resistance. Diabetes Res Clin Pract 83, 257-262, 2009.

Mahmoud AM, Ashour MB, Abdel-Moneim A, Ahmed OM. Hesperidin and naringin attenuate hyperglycemiamediated oxidative stress and proinflammatory cytokine production in high fat fed/streptozotocin-induced type 2 diabetic rats. J Diabetes Complications 26, 483-490, 2012.

Maritim AC, Sanders RA, Watkins JB. Diabetes, oxidative stress, and antioxidants: a review. J Biochem Mol Toxicol, $1724-1738,2003$.

Masiello P, Broca C, Gross R, Roye M, Manteghetti M, Hillaire-Buys D, Novelli M, Ribes G. Experimental NIDDM: development of a new model in adult rats administered streptozotocin and nicotinamide. Diabetes 47, 224229, 1998.

Masiello P. Animal models of type 2 diabetes with reduced pancreatic beta-cell mass. Int J Biochem Cell Biol 38, 873-893, 2006.

Matthews DR, Hosker JP, Rudenski AS, Naylor BA, Treacher DF, Turner RC. Homeostasis model assessment: insulin resistance and beta-cell function from fasting plasma glucose and insulin concentrations in man. Diabetalogia 28, 412-419, 1985. 
Mauvais-Jarvis F, Virkamaki A, Michael MD, Winnay JN, Zisman A, Kulkarni RN, Kahn CR. A model to explore the interaction between muscle insulin resistance and beta-cell dysfunction in the development of type 2 diabetes. Diabetes 49, 2126-2134, 2000.

Mills BJ, Lindeman RD, Lang CA. Magnesium deficiency inhibits biosynthesis of blood glutathione and tumor growth in the rat. Proc Soc Exp Biol Med 181, 326-332, 1986.

Mooren FC, Kruger K, Volker K, Golf SW, Wadepuhl M, Kraus A. Oral magnesium supplementation reduces insulin resistance in non-diabetic supplementation reduces insulin resistance in non-diabetic subjects - a doubleblind, placebo-controlled, randomized trial. Diabet Obes Metab 13, 281-284, 2011.

Moraes-Vieira PM, Saghatelian A, Kahn BB. GLUT4 expression in adipocytes regulates de novo lipogenesis and levels of a novel class of lipids with antidiabetic and anti-inflammatory effects. Diabetes 65, 1808-1815, 2016.

Nadler JL, Buchanan T, Natarajan R, Antonipillai I, Bergman R, Rude R. Magnesium deficiency produces insulin resistance and increased thromboxane synthesis. Hypertension 21, 1024-1029, 1993.

National Research Council (US) Committee for the Update of the Guide for the Care and Use of Laboratory Animals. Guide for the Care and Use of Laboratory Animals. 8th edition. Washington (DC): National Academies Press (US); 2011.

Okada T, Kawano Y, Sakakibara T, Hazeki O, Ui M. Essential role of phosphatidylinositol 3-kinase in insulin-induced glucose transport and antilipolysis in rat adipocytes: studies with a selective inhibitor wortmannin. J Biol Chem 269, 3568-3573, 1994.

Okuno S, Akazawa S, Yasuhi I, Kawasaki E, Matsumoto K, Yamasaki H, Matsuo H, Yamaguchi Y, Nagataki S. Decreased expression of the GLUT4 glucose transporter protein in adipose-tissue during pregnancy. Horm Metab Res 27, 231-234, 1995.

Paolisso G, Scheen, A, D’Onofrio F, Lefebvre P. Magnesium and glucose homeostasis. Diabetologia 33, 511-514, 1990.

Rude RK. "Magnesium” in Modern Nutrition in Health and Disease, Ross AC, Caballero B, Cousins RJ, Tucker KL, Ziegler TR, Eds., pp. 159-175, Lippincott Williams \& Wilkins, Baltimore, Md., USA, 11th edition, 2012.

Soltani N, Keshavarz M, Sohanaki H, Dehpour AR, Zahedi AS. Oral magnesium administration prevents vascular complications in STZ-diabetic rats. Life Sci 76, 1455-1464, 2005a.

Soltani N, Keshavarz M, Sohanaki H, Zahedi AS, Dehpour AR. Relaxatory effect of magnesium on mesenteric vascular beds differs from normal and streptozotocin induced diabetic rats. Eur J Pharmacol 508, 177-181, 2005 b.

Soltani N, Keshavarz M, Minaii B, Mirershadi F, Zahedi AS, Dehpour AR. Effect of administration of oral magnesium on plasma glucose and pathological changes in the aorta and pancreas of diabetic rats. Clin Exp Pharmacol Physiol 32, 604-610, 2005c.

Soltani N, Keshavarz M, Dehpour AR. Effect of oral magnesium sulfate administration on blood pressure and lipid profile in Streptozotocin diabetic rat. Eur J Pharmacol 560, 201-205, 2007.

Soltani N, Qiu H, Aleksic M, Glinka Y, Zhao F, Liu R. GABA exerts protective and regenerative effects on islet beta cells and reverses diabetes. Proc Natl Acad Sci 108, 11692-11697, 2011.

Song Y, He K, Levitan EB, Manson JE, Liu S. Effects of oral magnesium supplementation on glycaemic control in type 2 diabetes: a meta-analysis of randomized double-blind controlled trials. Diabet Med 23, 1050-1056, 2006.

Tahara A, Matsuyama-Yokono A, Nakano R, Someya Y, Shibasaki M. Hypoglycaemic effects of anti-diabetic drugs in streptozotocin-nicotinamide-induced mildly diabetic and streptozotocin-induced severely diabetic rats. Basic Clin Pharmacol Toxicol 103, 560-568, 2008.

Taheri Rouhi SZ, Sarker MMR, Rahmat A, Alkahtani SA, Othman F. The effect of pomegranate fresh juice versus pomegranate seed powder on metabolic indices, lipid profile, inflammatory biomarkers, and the histopathology of pancreatic islets of Langerhans in streptozotocin-nicotinamide induced type 2 diabetic SpragueDawley rats. BMC Complement Altern Med 17, 156, 2017.

Takaya J, Higashino H, Kobayashi Y. Intracellular magnesium and insulin resistance. Magnes Res 17, 126-136, 2004.

Tangvarasittichai S. Oxidative stress, insulin resistance, dyslipidemia and type 2 diabetes mellitus. World J Diabetes 6, 456-480, 2015.

Uchiyama M, Mihara M. Determination of malonaldehyde precursor in tissues by thiobarbituric acid test. Anal Biochem 86, 271-278, 1978.

van Dooran DR, Liejdekker CM, Handerson PT. Synergistic effects of phorone on the hepatotoxicity of bromobenzene and paracetamol in mice. Toxicol 11, 225-233, 1978.

Vasconcelos EM, Degasperi GR, de Oliveira HC, Vercesi AE, de Faria EC, Castilho LN. Reactive oxygen species generation in peripheral blood monocytes and oxidized LDL are increased in hyperlipidemic patients. Clin Biochem 42, 1222-1227, 2009. 
Vicario PP, Bennun A. Separate effects of Mg2+, MgATP, and ATP4- on the kinetic mechanism for insulin receptor tyrosine kinase. Arch Biochem Biophys 278, 99-105, 1990.

Vinals F, Camps M, Testar X, Palacin M, Zorzano A. Effect of cations on the tyrosine kinase activity of the insulin receptor: inhibition by fluoride is magnesium dependent. Mol Cell Biochem 171, 69-73, 1997.

Volpe SL. Magnesium in disease prevention and overall health. Adv Nutr 4, 378S-383S, 2013.

Watson RT, Kanzaki M, Pessin JE. Regulated membrane trafficking of the insulin-responsive glucose transporter 4 in adipocytes. Endocr Rev 25, 177-204, 2004.

Wu Y, Lu H, Yang H, Li C, Sang Q, Liu X, Liu Y, Wang Y, Sun Z. Zinc stimulates glucose consumption by modulating the insulin signaling pathway in L6 myotubes: essential roles of AktGLUT4, GSK3beta and mTOR-S6K1. J Nutr Biochem 34, 126-135, 2016.

Yamada K, Yamakawa K, Terada Y, Kawaguchi K, Sugaya A, Sugiyama T, Toyoda N. Expression of GLUT4 glucose transporter protein in adipose tissue and skeletal muscle from streptozotocin-induced diabetic pregnant rats. Horm Metab Res 31, 508-513, 1999.

Yan ST, Li CL, Tian H, Li J, Pei Y, Liu Y, Gong YP, Fang FS, Sun BR. MiR-199a is overexpressed in plasma of type 2 diabetes patients which contributes to type 2 diabetes by targeting GLUT4. Mol Cell Biochem 397, 45-51, 2014.

Yavuz Y, Mollaoglu H, Yurumez Y, Ucok K, Duran L, Tunay K, Akgun L. Therapeutic effect of magnesium sulphate on carbon monoxide toxicity-mediated brain lipid peroxidation. Eur Rev Med Pharmacol Sci 17, 28-33, 2013.

Zhang W, Zhao J, Wang J, Pang X, Zhuang X, Zhu X. Hypo-glycemic effect of aqueous extract of seabuckthorn (Hippophae rhamnoides L.) seed residues in streptozotocin-induced diabetic rats. Phytother Res 24, 228-232, 2010.

Zisman A, Peroni OD, Abel ED, Michael MD, Mauvais-Jarvis F, Lowell BB, Wojtaszewski, JF, Hirshman MF, Virkamaki A, Goodyear LJ. Targeted disruption of the glucose transporter 4 selectively in muscle causes insulin resistance and glucose intolerance. Nat Med 6, 924-928, 2000. 